\title{
Antidiabetic activity of Neolamarckia cadamba (Roxb.) Bosser flower extract in alloxan-induced diabetic rats
}

Shirajum Munira', Luthfun Nesa², Md. Siddiqul Islam¹, Yesmin Begum', Mohammad A. Rashid ${ }^{3}$, Moklesur Rahman Sarker ${ }^{2}$ and Tufael Ahmed ${ }^{2^{*}}$ (D)

\begin{abstract}
Background: Various parts i.e., stem bark, leaf, root and flower of Neolamarckia cadamba (Roxb.) Bosser has been extensively used by traditional practitioners to treat all types of diabetes. Our present study investigated the antidiabetic property of the extract from its flower and evaluated its traditional use for diabetes.

Results: Phenolic contents were found to be higher in the methanol soluble fraction (MESF) $(228.16 \pm 0.32 \mathrm{GAE} / \mathrm{g}$ of sample) while flavonoids were greater in quantity in the chloroform soluble fraction (CSF) (291 \pm 5.99 QE/g of sample). The MESF showed the highest free radical scavenging and a-amylase inhibitory potential with $I C_{50}$ value of $30.52 \pm 2.40$ and $6.26 \pm 0.82 \mu \mathrm{g} / \mathrm{mL}$ respectively and both the values were promising when compared to the individual standards. Highest reduction of blood glucose level were observed when the $\mathrm{N}$. cadamba flower extract (NCFE) were given (not in combination with metformin) orally for 2 weeks. NMCE at $500 \mathrm{mg} / \mathrm{kg}$ resulted $60.2 \%$ ( $p<$ 0.05) reduction of blood glucose in the diabetic group, comparable with the effect of standard metformin (68.4\%). Gain in body weight were also observed in the test groups indicating an overall improvement of health in the diabetic rats.

Conclusions: The extract of Neolamarckia cadamba (Roxb.) flower is rich in phenolic and flavonoid compounds attributing to its potent in vitro antioxidant and a-amylase inhibitory potential. Oral administration of NCFE also resulted in a significant $(p<0.05)$ dose dependent reduction of blood glucose level in diabetic rats, while no synergistic activity was observed when it was given in combination with metformin. These findings imply the possible pharmacological mechanisms behind the antidiabetic property of NCFE could be: inhibition of a-amylase and delaying the absorption of glucose from the intestine, secondly possessing 'metformin like' activity such as increasing cellular uptake and glycolysis of glucose, reducing gluconeogenesis in the liver etc. This study also for the first time provides scientific evidence in favor of the traditional use N. cadamba flower against diabetes and demands future study in order to isolate and characterize the bioactive compounds responsible for such bioactivities.
\end{abstract}

Keywords: Antidiabetic, Antihyperglycemic, Neolamarckia cadamba, Kodom, a-Amylase

\footnotetext{
* Correspondence: tufael@sub.edu.bd

2Department of Pharmacy, State University of Bangladesh, 77 Satmasjid road,

Dhanmandi, Dhaka 1207, Bangladesh

Full list of author information is available at the end of the article
}

\section{Springer Open}

(c) The Author(s). 2020 Open Access This article is licensed under a Creative Commons Attribution 4.0 International License, which permits use, sharing, adaptation, distribution and reproduction in any medium or format, as long as you give appropriate credit to the original author(s) and the source, provide a link to the Creative Commons licence, and indicate if changes were made. The images or other third party material in this article are included in the article's Creative Commons licence, unless indicated otherwise in a credit line to the material. If material is not included in the article's Creative Commons licence and your intended use is not permitted by statutory regulation or exceeds the permitted use, you will need to obtain permission directly from the copyright holder. To view a copy of this licence, visit http://creativecommons.org/licenses/by/4.0/. 


\section{Background}

Diabetes mellitus is a metabolic disorder resulting in increased blood glucose level in blood, manifested due to either lack of glucose metabolism (decreased insulin secretion) or glucose reuptake (decreased sensitivity towards insulin) [1]. Among the adults (age 20-79 years) with diabetes in the top five South East Asian countries, Bangladesh is in the second position. The number of people with diabetes in Bangladesh was 5.10 million in 2013, which is expected to reach 8.20 million by 2035 [2]. Diabetes is a chronic, incurable disease that requires lifelong management using conventional nonpharmacological (diet, exercise and surgery) and/or pharmacological means (insulin and oral hypoglycemic agents). These conventional approaches are very costly which often leads people in developing countries to seek help in alternative traditional medicines alongside the allopathic treatment $[1,3]$.

Neolamarckia cadamba (Roxb.) Bosser (family Rubiaceae), locally known as 'Kodom', is widely distributed throughout Bangladesh and in others countries of South Asia [4]. N.cadamba is extremely popular among the traditional health practitioners and almost every part of the plant has medicinal values and used to treat ailments such as fever, anemia, and tumor, improve the quality of semen and diabetes etc. [5]. The biological activities that has already been reported include the antidiabetic (stem bark), analgesic (stem bark, leaf), antidiarrheal (flowering top) and hypolipidemic (root) properties etc. [6]. However, no scientific data has yet been published regarding the antidiabetic property of its flower. Therefore our current study aimed to evaluate the antidiabetic potential of NCFE (individually or in combination with metformin) both in vitro and in vivo, validate its safety and efficacy as a traditional medicine and finally propose plausible mechanism(s) contributing to its pharmacological activities.

\section{Methods \\ Collection of plant material and preparation of the crude methanol extract of $N$. cadamba}

Fresh flowers of $N$. cadamba were collected during the month of August 2015 from the district of Sirajganj, Bangladesh. The flower sample were authenticated by the Bangladesh National Herbarium, Mirpur, and sample specimen were submitted for future referencing purpose. The collected flowers were then sun dried for several days followed by heating in the oven for a $24 \mathrm{~h}$. period but at low temperature $\left(<40^{\circ} \mathrm{C}\right)$. The dried fruits were then grounded into coarse powder using high capacity grinding machine in the Phytochemical Research Laboratory, State University of Bangladesh. $600 \mathrm{~g}$ of the powdered material were measured, equally divided into two parts (300 g each) and later transferred into 2 amber colored reagent bottles both containing $2.0 \mathrm{~L}$ of methanol and chloroform. The containers with their contents were sealed by bottle cap and kept for a period of 15 days accompanied by occasional shaking and stirring. The mixtures were then filtered several times using fresh cotton plug and finally with Whatman No.1 filter paper. The volume of the filtrates were then allowed to evaporate at ambient temperature until approximately $70 \%$ solvents were evaporated. The leftover slugs were used as the crude methanol and chloroform extracts respectively [7].

\section{Chemicals used}

Folin-Ciocalteu reagent, vincristine sulfate and alloxan were the products of Sigma chemical company, USA. BHT was manufactured by Merck, Germany. Gallic acid was purchased from Wako pure chemicals Ltd., Japan and metformin from Chadwell health essex, England. All the materials were ensured to be of analytical grade.

\section{Animal experiments}

Nine weeks old male White-Evans rat (100-120 g) were purchased from Jahangirnagar University (JU), Dhaka, Bangladesh and kept in animal cages under standard environmental conditions $\left(22-25^{\circ} \mathrm{C}\right.$, humidity $60-70 \%, 12 \mathrm{~h}$ light: $12 \mathrm{~h}$ dark cycle). During the in vivo bioassay (14 days), all the rats were fed with standard laboratory diet (Purina rat chow) obtained from the JU and water ad libitum. All procedures were performed according to the institutional guidelines for animal experimentation of Department of Pharmacy, State University of Bangladesh. The animals were randomly assigned into group I, II, III, $\mathrm{IV}, \mathrm{V}$ and VI; 5 rats in each group following the respective treatment protocols for the determination of blood glucose level. Two groups (I and II) were treated as the normal and the diabetic control respectively. Groups III and IV received the crude extract at two different doses. Group V served as the positive control and Group VI received the combined dose of Metformin and NCFE.

\section{Collection of blood and analytical procedure}

Blood samples were collected from the tail vein of the rats followed by measurement using the glucose monitoring system purchased from Tyson Bioresearch, Based Industrial Park, Chu-Nan, Taiwan.

\section{Determination of total phenolic and flavonoid content}

Total phenolic content of various fractions of NCFE were determined employing the method described by Singleton et al, 1965, involving the Folin-Ciocalteu reagent as the oxidizing agent, gallic acid as the standard and the results expressed as the milligram of gallic acid equivalent (GAE) per gram of plant extract [8]. The total flavonoid content was determined using the well-known aluminum chloride colorimetric method and the results 
expressed as the milligram of quercetin equivalent (QE) per gram of plant extract [9].

\section{Determination of antioxidant activity}

The widely used method of Brand-William et. al., 1995 were followed in order to assess the antioxidant activity of the soluble fractions [7]. The antioxidant potential was evaluated by the ability of the fractions to neutralize the radicals of 1, 1-diphenyl-2-picrylhydrazyl (DPPH) and compared with the standard Tetra-butyl-1-hydroxytoluene (BHT). The $\mathrm{IC}_{50}$ value, concentration of reagent required to neutralize $50 \%$ of the oxidant molecule, was calculated using the formula:

Percent inhibition $=\left(1-\mathrm{A}_{1} / \mathrm{A}_{0}\right) \times 100 \%$.

Here, $\mathrm{A}_{0}=$ absorbance of the blank (methanol).

$\mathrm{A}_{1}=$ absorbance of the sample being analyzed.

\section{In vitro antidiabetic activity}

The $\alpha$-amylase inhibitors are a class of antidiabetic drugs that block the hydrolysis of carbohydrates, decreasing its absorption from the gastrointestinal tract and aiding in controlling the blood glucose level [10]. The in vitrooamylase inhibitory test were performed following the method of Bhandari et al., 2003, using acarbose (ABS) as the reference standard [11].

\section{In vivo antidiabetic activity}

The in vivo antidiabetic potential of the plant extracts were analyzed exclusively as well as in combination with metformin, after inducing diabetes in White-Evans rat by alloxan $(120 \mathrm{mg} / \mathrm{kg}$.bd.wt.) as mentioned in the works of Pari et al., 2002 [12]. NCFE at doses 250 and $500 \mathrm{mg} /$ kg.bd.wt. and metformin at $850 \mathrm{mg} / \mathrm{kg}$.bd.wt. were given orally to group III, IV and V respectively for consecutive 14 days. Same procedures were followed for group VI receiving the combined dose of NCFE $(250 \mathrm{mg} / \mathrm{kg})$ and metformin $(425 \mathrm{mg} / \mathrm{kg})$. Blood glucose level were monitored using glucose monitoring system purchased from Tyson Bioresearch, Based Industrial Park, Chu-Nan, Taiwan.

\section{Data analysis}

All the results were recorded in triplicates and results expressed as the mean \pm standard error mean (SEM). In order to determine statistical significance between groups, Dunnett's test and One way ANOVA were performed using SPSS version 25.0 and $p<0.05$ was considered to be statistically significant.

\section{Results}

Percentage yield, total phenolic and flavonoid content After soaking $300 \mathrm{~g}$ of the powdered material, the final weight of the crude fractions of methanol and chloroform extracts were found to be $39.08 \mathrm{~g}$ and $25.41 \mathrm{~g}$, obtaining a percentage yield $13.02 \%$ and $8.47 \%$. Among the two extractives, the MESF (228.16 mg of GAE / gm. of dried extract) had the highest phenolic content than the CSF (60.45 mg of GAE / gm. of dried extract). However, the flavonoids were present in higher quantity in the CSF (291 mg of GAE / gm. of dried extract) compared to the MESF (19.33 mg of GAE / gm. of dried extract) (Table 1).

\section{Antioxidant activity}

The MESF possessed the highest antioxidant activity among the two fractions with $\mathrm{IC}_{50}$ value of $30.52 \pm$ $2.40 \mu \mathrm{g} / \mathrm{ml}$ when compared to the standard ascorbic acid $(16.97 \pm 0.41 \mu \mathrm{g} / \mathrm{ml})($ Table 1$)$.

\section{In vitro Antidiabetic activity}

The $\mathrm{IC}_{50}$ value of MESF, CSF and the standard acarbose in the in vitro $\alpha$-amylase inhibitory assay were $6.26 \pm$ $0.82,6.50 \pm 0.63$ and $5.80 \pm 0.77 \mu \mathrm{g} / \mathrm{ml}$ respectively. Even though MESF possessed slightly higher enzyme inhibitory potential than CSF, both the results were promising and comparable to acarbose (Table 1).

\section{In vivo Antidiabetic activity}

The 14 days long oral administration of NCFE in the diabetic rat resulted in a gradual dose dependent decrease in glucose concentration in the blood. The NCFE at $500 \mathrm{mg}$, resulted in a significant $(p<0.05)$ reduction of blood glucose level by $58.70 \%$ when compared to the $68.4 \%(\mathrm{p}<0.05)$ reduction by the standard metformin. The combined dose of NCFE $(250 \mathrm{mg})$ and metformin $(425 \mathrm{mg})$ also managed to significantly $(\mathrm{p}<0.05)$ reduce blood glucose concentration when compared with the diabetic control group but the percentage reduction (57.64\%) were lower compared to the individual single dose of NCFE and metformin (Fig. 1). The crude extract alone at two different doses and in combination with metformin also resulted in weight gain in the test animals by 135,145 and $150 \mathrm{~g}$ respectively indicating an overall improvement in the health of the diabetic rats (Fig. 2).

\section{Discussion}

The evaluation of the blood glucose level lowering ability of the NCFE has significant implications on its therapeutic use. The preliminary phytochemical screening of this study has indicated the presence of phenolics and flavonoids in NCFE which might be responsible for its high antioxidant property [13]. Furthermore, flavonoids have been attributed to stimulate insulin secretion in vivo or possess insulin like effect $[14,15]$.

The in vitro analysis has also revealed for the first time that the partitions of NCFE could inhibit the $\alpha$-amylase enzyme in the stomach and retard carbohydrate 
Table 1 Total phenolic content, total flavonoid content, antioxidant, and a-amylase inhibitory activity of various soluble fractions of the crude extract of N.cadamba

\begin{tabular}{|c|c|c|c|c|}
\hline $\begin{array}{l}\text { Samples/ } \\
\text { Standards }\end{array}$ & $\begin{array}{l}\text { Total phenolic content (mg of GAE/g of } \\
\text { dried extract) }\end{array}$ & $\begin{array}{l}\text { Total flavonoid content (mg of QE/g of } \\
\text { dried extract) }\end{array}$ & $\begin{array}{l}\text { Antioxidant activity } \\
\mathrm{IC}_{\mathbf{5 0}}(\mu \mathrm{g} / \mathrm{ml})\end{array}$ & $\begin{array}{l}\text { a-amylase inhibition } \\
\mathrm{IC}_{50}(\mu \mathrm{g} / \mathrm{ml})\end{array}$ \\
\hline MESF & $228.16 \pm 0.32$ & $19.33 \pm 0.66$ & $30.52 \pm 2.40$ & $6.26 \pm 0.82$ \\
\hline CSF & $60.45 \pm 0.29$ & $291 \pm 5.99$ & $147.51 \pm 0.55$ & $6.50 \pm 0.63$ \\
\hline VS (std.) & - & & - & - \\
\hline ASC (std.) & - & & $16.97 \pm 0.41$ & - \\
\hline ABS (std.) & - & - & - & $5.80 \pm 0.77$ \\
\hline
\end{tabular}

MESF methanol extract soluble fraction, CSF chloroform soluble fraction, VS vincristine sulfate, $A S C$ ascorbic acid, GAE gallic acid equivalent, QE quercetin equivalent, $A B S$ acarbose, SEM standard error of mean, Std Standard

absorption similar to the antidiabetic drug acarbose. This finding provides pharmacological evidence behind the antidiabetic property of the plant extract and supports the use of this extract as an adjuvant for diabetes management.

Alloxan resulted in the destruction of beta cells in the pancreas [16], lowering insulin production ultimately increasing glycaemia. Oral administration of NCFE alone in the diabetic rats for 2 weeks resulted in the significant decrease blood glucose in a dose dependent manner. This hypoglycemic property of the NCFE could be attributed due to the stimulation of insulin secretion by the remaining beta cells or by increasing the uptake of glucose by increasing the insulin sensitivity. However, since alloxan is a well-known $\beta$-cytotoxic agent and the observations that NCFE alone induced glycaemia significantly in the alloxan treated rats lends credence that it has peripheral action similar to that of metformin. Metformin exhibits its glucose level lowering activity by several mechanisms such as: stimulation of glucose uptake by tissues from blood and subsequent intercellular glycolysis; reduced gluconeogenesis in the liver and kidney etc.; decreasing absorption of glucose from intestine by stimulating enterocytes to convert glucose to lactate and by lowering plasma glucagon level [17]. Therefore, the NCFE could show its glucose lowering ability by any or multiple mechanisms mentioned above. The combined administration of NCFE and metformin did not result in increased effect compared to individual therapy further corroborates the fact that the mechanism of action of NCFE and metformin are similar [1]. Furthermore, if the mechanism of action NCFE and metformin are similar, this additive effect could have other clinical implications. The traditional medicinal use of this plant could complement along with orthodox allopathic medication and result in better management of diabetes by lowering the dose of metformin and its associated side effects. The use of NCFE could also be included as a dietary supplement and can play a significant role in the management of either insulin dependent or non-insulin dependent

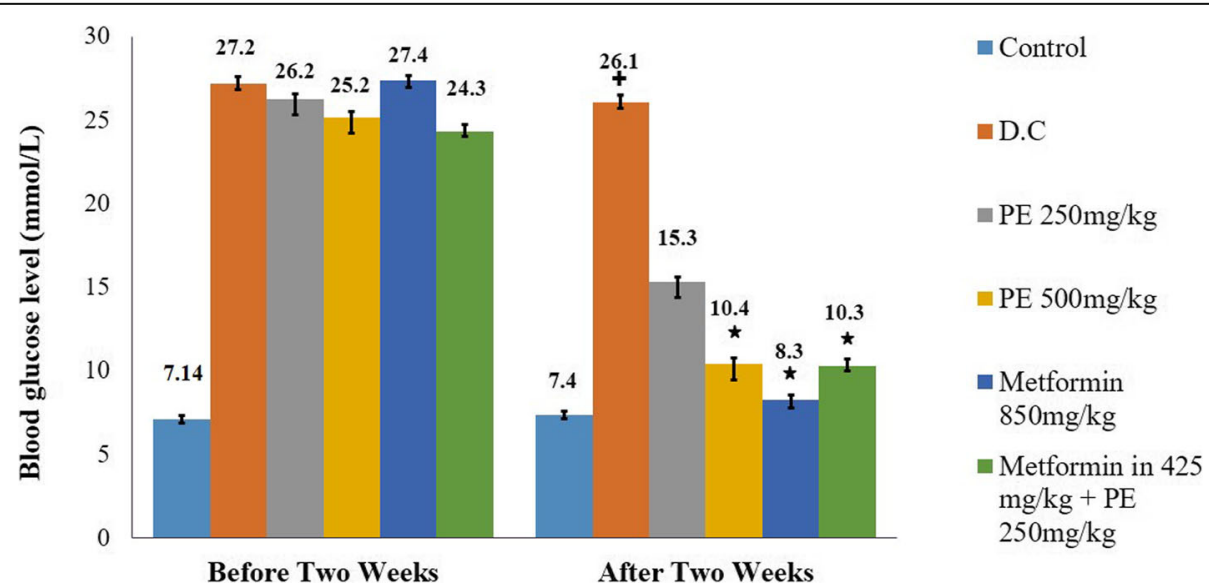

Fig. 1 Effect of the oral administration of $N$. cadamba flower extract on the blood glucose level in normal and diabetic rat. Effect of the oral administration of $\mathrm{N}$. cadamba flower extract (given separately at two different doses or in combination with the standard metformin) on the blood glucose level in normal and diabetic rat. Here, DC = Diabetic control, PE = Plant extract. All the values are expressed as mean \pm SEM, sample size $(n=5),\left(^{*}\right)$ indicates $p<0.05$ compared to diabetic control group, $(+)$ indicates $p<0.05$ compared to normal group 


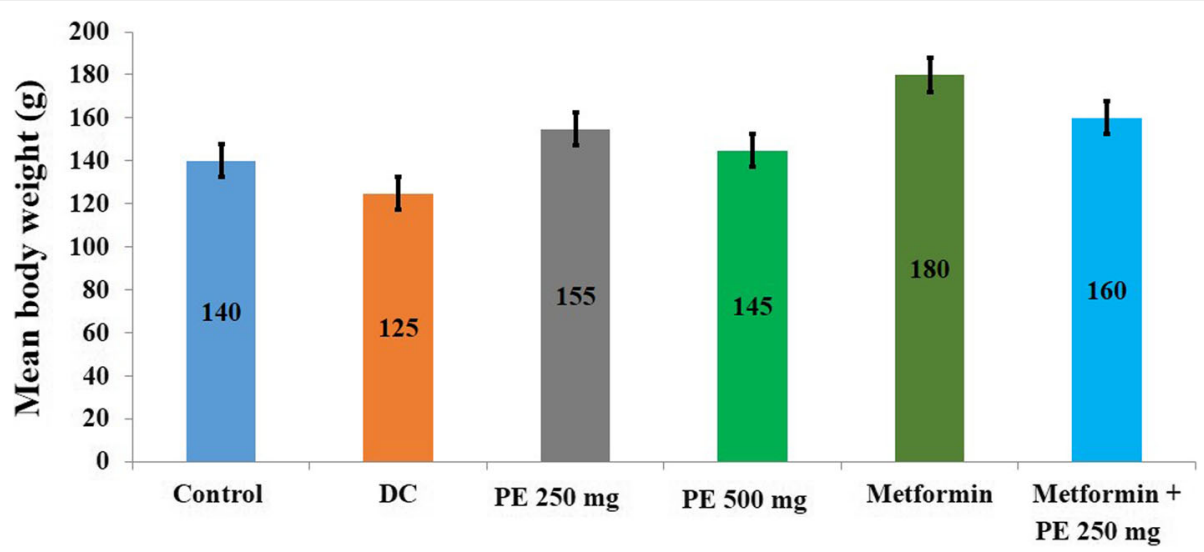

Fig. 2 Effect of the oral administration of $N$. cadamba flower extract on the mean body weight in normal and diabetic rat. Effect of the oral administration of $\mathrm{N}$. cadamba flower extract (given separately at two different doses or in combination with the standard metformin) on the mean body weight in normal and diabetic rat. Here, $\mathrm{DC}=$ Diabetic control, $\mathrm{PE}=$ Plant extract. All the values are expressed as mean $\pm \mathrm{SEM}$, sample size $(n=5)$, $\left(^{*}\right)$ indicates $p<0.05$ compared to diabetic control group, $(+)$ indicates $p<0.05$ compared to normal group

diabetes. There are evidences in past studies where a plant had been suggested to be included in the diet for diabetes management alongside allopathic therapy [18].

\section{Conclusions}

Even though various authors have already confirmed that the crude extracts of the leaf, stem bark and root of $N$. cadamba possess in vivo antidiabetic and other activities, our present study, for the first time, confirms the antidiabetic potential of extract from its flower and thereby supporting the traditional use of NCFE for treating diabetes. In terms of elucidating the plausible mechanism behind the antidiabetic activity of NCFE, the in vitro bioassay confirms that this crude extract has $\alpha$-amylase inhibitory potential. Furthermore, comparing the antidiabetic activity of NCFE with metformin it could be deduced that the in vivo antidiabetic activity by the NCFE is exerted by mechanisms similar by which metformin works and both targets the same molecular pathway. Moreover, the NCFE did not show any antihyperglycemic activity in normal animal group which indicates that the high safety profile and low side effects have aided its traditional use. This study should further stimulate the urge to continue experiments in order to isolate the phytoconstituents responsible for the antidiabetic activity of NCFE and also to confirm its mechanism of action.

\footnotetext{
Abbreviations

NCFE: Neolamarckia cadamba flower extract; JU: Jahangirnagar University; DPPH: 2,2-diphenyl-1-picrylhydrazyl; MESF: Methanol extract soluble fraction; CSF: Chloroform soluble fraction; DC: Diabetic control; SEM: Standard error mean; PE: Plant extract; ASC: Ascorbic acid; ASA: Acetyl salicylic acid; VS: Vincristine sulfate; IC: Inhibitory concentration; LC: Lethal concentration; GAE: Gallic acid equivalent; QE: Quercetin equivalent; BHT: Tetra-butyl-1hydroxytoluene; ABS: Acarbose; Std: Standard
}

\section{Acknowledgements}

The authors are grateful to the Department of Pharmacy, State University of Bangladesh, Bangladesh for providing necessary instrumental and other supports.

\section{Authors' contributions}

SM and YB designed the study. SM, YB and LN carried out the experiments. SM, YB, MSI and LN analyzed and discussed the data. TA and LN were the major contributors in writing this manuscript. MAR and MMRS had been involved in drafting the manuscript and revising it critically for important intellectual content. All authors read, agreed to be accountable for all aspects of the work and approved the final manuscript.

\section{Funding}

This research did not receive any specific grant from funding agencies in the public, commercial, or not-for-profit sectors.

\section{Availability of data and materials}

The datasets used and/or analyzed during the current study are available from the corresponding author on reasonable request. All data generated or analyzed during this study are included in this published article [and its supplementary information files].

\section{Ethics approval and consent to participate}

The experimental procedures on laboratory animals were approved by the Animal Ethical Committee of Pharmacy Department, State University of Bangladesh, Bangladesh.

\section{Consent for publication}

Not applicable.

\section{Competing interests}

The authors declare that they have no competing interests in this section.

\section{Author details}

'Department of Pharmacy, Southeast University, Banani, Dhaka 1213, Bangladesh. ${ }^{2}$ Department of Pharmacy, State University of Bangladesh, 77 Satmasjid road, Dhanmandi, Dhaka 1207, Bangladesh. ${ }^{3}$ Department of Pharmaceutical Chemistry, Faculty of Pharmacy, University of Dhaka, Dhaka 1000, Bangladesh. 
Received: 29 September 2019 Accepted: 20 May 2020

Published online: 27 May 2020

\section{References}

1. Michael UA, David BU, Theophine CO, Philip FU, Ogochukwu AM, Benson VA. Antidiabetic effect of combined aqueous leaf extract of Vernonia amygdalina and metformin in rats. J Basic Clin Pharm. 2010;1(3):197.

2. Hira R, Miah MA, Akash DH. Prevalence of type 2 diabetes mellitus in rural adults (> _31years) in Bangladesh. Faridpur Med Coll J. 2018;13(1):20-3.

3. Kadir MF, Sayeed MS, Mia MM. Ethnopharmacological survey of medicinal plants used by traditional healers in Bangladesh for gastrointestinal disorders. J Ethnopharmacol. 2013;147(1):148-56.

4. Ahmed F, Rahman S, Ahmed N, Hossain M, Biswas A, Sarkar S, Banna H, Khatun A. Evaluation of Neolamarckia cadamba (Roxb.) Bosser leaf extract on glucose tolerance in glucose-induced hyperglycemic mice. Afr J Tradit Complementary Altern Med. 2011;8(1). https://www.ajol.info/index.php/ ajtcam/article/view/60549.

5. Umachigi SP, Kumar GS, Jayaveera KN, Dhanapal R. Antimicrobial, wound healing and antioxidant activities of Anthocephalus cadamba. Afr J Tradit Complementary Altern Med. 2007;4(4):481-7.

6. Dubey A, Nayak S, Goupale DC. A review on phytochemical, pharmacological and toxicological studies on Neolamarckia cadamba. Der Pharm Let. 2011;3:45-54.

7. Brand-Williams W, Cuvelier M, And CB-L-F Science, 1995 U. use of a free radical method to evaluate antioxidant activity. LWT - Food Sci Technol 1995;28(1):25-30.

8. Singleton VL, Rossi JA. Colorimetry of total phenolics with phosphomolybdic-phosphotungstic acid reagents. Am J Enol Vitic. 1965; 16(3):144-58.

9. Chang CC, Yang MH, Wen HM, Chern JC. Estimation of total flavonoid content in propolis by two complementary colorimetric methods. J Food Drug Anal 2002 1;10(3).

10. Etxeberria U, de la Garza AL, Campión J, Martinez JA, Milagro Fl. Antidiabetic effects of natural plant extracts via inhibition of carbohydrate hydrolysis enzymes with emphasis on pancreatic alpha amylase. Expert Opin Ther Targets. 2012;16(3):269-97. https://www.tandfonline.com/doi/abs/10.1517/14 728222.2012.664134

11. Bhandari MR, Jong-Anurakkun N, Hong G, Kawabata J. a-Glucosidase and aamylase inhibitory activities of Nepalese medicinal herb Pakhanbhed (Bergenia ciliata, haw.). Food Chem. 2008;106(1):247-52.

12. Pari L, Saravanan G. Antidiabetic effect of cogent db, a herbal drug in alloxan-induced diabetes mellitus. Comp Biochem Physiol C Toxicol Pharmacol. 2002;131(1):19-25.

13. Pietta PG. Flavonoids as antioxidants. J Nat Prod. 2000;63(7):1035-42.

14. Bussa SK, Jyothi P. Antidiabetic activity of stem bark of Neolamarckia cadamba in alloxan induced diabetic rats. Int J Pharm Technol. 2010;2(2): $314-24$.

15. Gurjar H, Jain SK, Irchhaiya R, Nandanwar R, Sahu VK, Saraf H. Hypoglycemic effects of methanolic extract of Anthocephalus cadamba bark in alloxan induced diabetic rats (Rox B) Miq. Int J Pharm Sci Res. 2010;1(3):79-83.

16. Lazarow A. Alloxan diabetes and mechanism of $\beta$-cell damage by chemical agents. Exp Diab. 1964;4:49-69.

17. Shlafer M, Marieb EN, Nelson R. The nurse, pharmacology, and drug therapy. Addison-Wesley Publishing Company, Health Sciences; 1989.

18. Falcão-Pires I, Leite-Moreira AF. Diabetic cardiomyopathy: understanding the molecular and cellular basis to progress in diagnosis and treatment. Heart Fail Rev. 2012;17(3):325-44. https://link.springer.com/article/10.1007/s10741011-9257-z.

\section{Publisher's Note}

Springer Nature remains neutral with regard to jurisdictional claims in published maps and institutional affiliations.

\section{Submit your manuscript to a SpringerOpen ${ }^{\odot}$ journal and benefit from:}

- Convenient online submission

- Rigorous peer review

- Open access: articles freely available online

- High visibility within the field

- Retaining the copyright to your article

Submit your next manuscript at $\gg$ springeropen.com 